\title{
Rapid Real Time PCR Based Detection of Cell Count in Case of Urinary Tract Infection
}

\author{
${ }^{1}$ Poulomi Nandy, ${ }^{2}$ Ashoke Ranjan Thakur and ${ }^{1}$ Shaon Ray Chaudhuri \\ ${ }^{1}$ Department of Biotechnology, School of Biotechnology and Biological Sciences, \\ West Bengal University of Technology, BF-142, Sector-1, Salt Lake, Kolkata-700064, West Bengal, India \\ ${ }^{2}$ Techno India University, Vice Chancellor's Office \\ EM4, sector V, Salt Lake, Kolkata-700091, West Bengal, India
}

Received 2012-12-05, Revised 2013-04-25; Accepted 2013-05-10

\begin{abstract}
Microbial identification and antimicrobial susceptibility testing methods currently used in clinical microbiology laboratories require at least two to three days because they rely on the growth and isolation of micro-organisms. This long, but necessary, delay has enormous consequences on prophylactic usage of antimicrobial drugs. This study was an attempt to reduce this detection time span. Taq Man Real Time PCR has been used as an important tool in the differentiation of Gram nature of bacteria present in UTI patients that allows detection of spiked bacterial $16 \mathrm{~S}$ rDNA from urine samples within a short span of $5 \mathrm{~h}$ and also gives us the corresponding cell count of both/either Gram positive and negative organisms present. A standard curve was generated which was used to determine the cell count of control as well as patient samples. Detection could be done in the range of $10^{3}$ to $10^{6}$ cells $/ \mathrm{mL}$ Patient samples screened clustered either in the allele 1 or allele 2 axes, depending on majority concentration of Gram nature of the microorganisms. The cell counts for control individuals were scattered within 0 to $10^{2}$, while very few in the range of $10^{4}$. The case was just reverse for patient group, where most of the points were scattered within $10^{4}$ to $10^{8}$. Thus the optimal selection of appropriate antimicrobials (depending on the gram nature) by clinicians, will be gradually improved as an increasing number of rapid molecular diagnostic tools for the detection, identification and characterization of infectious agents become commercially available.
\end{abstract}

Keywords: Allelic Discrimination Plot, Genotypic Assay, Gram Nature, Realtime PCR, Standard Curve

\section{INTRODUCTION}

The urinary tract is one of the most common sites of bacterial infection in women (Foxman, 2003; Ishaq et al., 2011). These infections also carry the risk of possible progression to bacteremia. The empirical choice of an effective treatment is becoming more difficult as urinary pathogens are increasingly becoming resistant to commonly used antibiotics (Nicolle et al., 1996; Barret et al., 1999; Mathai et al., 2001; Karlowsky et al., 2001; Ishaq et al.,
2011; Dharmadhikari and Peshwe, 2009; Butcu et al., 2011; Ultley et al., 1988; Leclerq et al., 1988; Ishaq et al., 2011). Any infection left untreated like UTI, kidney infection, is extremely dangerous and can lead to life threatening conditions such as bacteremia. This is usually a very serious condition that results in death unless prompt appropriate treatment is provided.

One of the major drawbacks of the routine diagnostic methods for pathogen identification in UTI is the long period for detection (48 to $72 \mathrm{~h}$ ) required in $\begin{aligned} \text { Corresponding author: } & \text { Shaon Ray Chaudhuri, Department of Biotechnology, School of Biotechnology and Biological Sciences, } \\ & \text { West Bengal University of Technology, BF-142, Sector-1, Salt Lake, Kolkata-700064, West Bengal, India } \\ & \text { Tel: 00913323210731 Fax: 00913323341030 }\end{aligned}$ 
culture based methods (Ramlakhan et al., 2011). Besides, uncultivable microbes are numerically dominant in biological samples, urine being no exception and therefore have to be detected by culture independent methods (Carroll et al., 2000; Belgrader et al., 1998; Bittar et al., 2008; Bergeron and Ouellette, 1995; Picard and Bergeron, 1999; Tang et al., 1997; Ishaq et al., 2011). The total count (cultivable as well as non-cultivable bacteria that are alive, but do not give rise to visible growth under non-selective growth conditions) needs to be detected rapidly for prompt medical intervention.

The delay of the microbiology laboratory contrasts with the time required (less than one hour) to get the results from other hospital laboratories or departments, such as biochemistry, hematology and radiology. Indeed, clinical microbiology procedures remain still based on the use of a variety of growth-dependent biochemical tests developed by Pasteur and others during the 19th and 20th centuries. Consequently, physicians rarely consult the microbiology results unless the patient is not responding to the initial antimicrobial therapy, which is based on key information obtained during the first hour after patient admission, thereby excluding any diagnosis based on microbiology results. Clearly, there is a need for rapid and accurate diagnostic tests for use in clinical microbiology laboratories to enable optimal patient management and treatment. Rapid detection and identification of microbial pathogens and their antimicrobial resistance profiles would have a tremendous impact on the practice of medicine by providing physicians with key microbiology results when needed.

The use of rapid molecular diagnostics may provide a solution for treating this disease which has a high morbidity and mortality rate. Molecular biology techniques for correct detection and identification of bacteria is now widely used in clinical microbiology namely $16 \mathrm{~S}$ rRNA based identification, terminal Restriction Fragment Length Polymorphism (tRFLP), Random Amplification of Polymorphic DNA (RAPD), Real Time PCR (Picard and Bergeron, 2002; Ishaq et al., 2011). There are innumerable number of patents (USPTO 20090239248, USPC 4356, US Patent 7205111, US Patent 7662562, US Patent 4693972) stating methodologies for rapid identification of microbes from clinical samples, but none of them mention the sensitivity of detection. Keeping this fact in mind we tried to fine-tune already existing methods to develop a more sophisticated system of detection. Real Time PCR has been used as an important tool in the differentiation of Gram nature of bacteria present in UTI patients using a consensus real-time PCR protocol with a TaqMan probe that allows detection of spiked bacterial 16S rDNA from urine samples within a short span of $5 \mathrm{~h}$ and also gives us the corresponding cell count of both/either Gram positive and negative organisms present.

\section{MATERIALS AND METHODS}

\subsection{Genomic DNA Isolation}

Bacterial genomic DNA was extracted using Fit Amp Urine DNA Isolation Kit (Epigentek, P-1017-050) from various dilutions $\left(10^{8}\right.$ to $10^{1}$ cells $\left./ \mathrm{mL}\right)$ of urine samples. Cartridge based DNA extraction kit was used for isolation of DNA as per manufacturer's protocol with minor modifications. $900 \mu \mathrm{l}$ of sterile urine (urine samples were filtered by passing them through a $0.22 \mu$ syringe filter) was taken and seeded with culture of gram negative (E.coli) and gram positive (S.aureus) bacteria separately at a concentration of $10^{1}, 10^{2}, 10^{3}, 10^{4}, 10^{5}$, $10^{6} 10^{7}$ and $10^{8}$ cells $/ \mathrm{mL}$. The suspension was centrifuged at $10,000 \mathrm{rpm}$ for 10min (Eppendorf Centrifuge 5418, Rotor eppendorf FA-45-18-11 aerosol tight) at room temperature to pellet down the cells. The supernatant was discarded and the pellet was resuspended in $200 \mu \mathrm{L}$ of suspension buffer and mixed through pipetting. Then $4 \mu \mathrm{L}$ of DNA digestion buffer containing enzyme was added and mixed using vortex. The mixture was incubated at $65^{\circ} \mathrm{C}$ for $1 \mathrm{~h}$. To it $300 \mu \mathrm{l}$ of DNA capture buffer was added and mixed using pipettman. The mixture was transferred to a spin column placed inside a $2 \mathrm{~mL}$ collection tube. It was centrifuged at 12,000rpm for $1 \mathrm{~min}$ (Eppendorf Centrifuge 5418, Rotor eppendorf FA-45-18-11 aerosol tight). The flow through was discarded and the spin column was replaced in the collection tube. The centrifugation step was repeated again and the supernatant was discarded. Then $300 \mu \mathrm{L}$ of $70 \%$ ethanol was added to the spin column and centrifuged at $12,000 \mathrm{rpm}$ for $30 \mathrm{sec}$ (Eppendorf Centrifuge 5418, Rotor eppendorf FA-45-18-11 aerosol tight). The flow through was discarded. Two more washes of $200 \mu \mathrm{L}$ of $90 \%$ ethanol were applied similarly as stated above. This was to remove salts as well as to wash away impurities. The spin column was replaced into a fresh $1.5 \mathrm{mLcentrifuge}$ tube and the DNA was eluted using $10 \mu \mathrm{L}$ of DNA elution buffer.

\subsection{Real Time PCR}

The DNA obtained was directly used for gram nature detection using the TaqMan PCR protocol (Genotypic assay) as reported by Shigemura et al. (2005) and Ishaq et al. (2011) to check the sensitivity of the assay. The only modification was that for Probe 2, FAM was used in place of TET in order to maintain the compatibility of our Real time PCR Step One system. ROX was used for internal control. The allelic discrimination assay (Genotyping) was set up in a 48 well reaction plate. Each experiment was repeated at least 6 times. 
For determination of the standard curve, sterile urine samples (post filtration through $0.22 \mu$ syringe filter units by Whatman) were seeded with $1 \mathrm{E} 7$ concentration of Gram positive (S aureus) bacteria. Genomic DNA was extracted using Fit Amp Urine DNA Isolation Kit as mentioned above. The DNA was serial diluted (corresponding to $1 \mathrm{E} 1$ to $1 \mathrm{E} 7$ cells) and real time experiment was set up exactly the similar way as already mentioned above, under Standard Curve option. Patient urine samples were also analyzed based on the standard curve equation to determine the cell count. A total number of 70 non-infected and 89 patient samples were analyzed and their corresponding $\mathrm{C}_{\mathrm{T}}$ values for both Gram positive and Gram negative bacteria were noted down.

\section{RESULTS}

Seeded sterile urine was used to check the efficiency of detection/sensitivity of this assay. Detection could be done in the range of $10^{3}$ to $10^{6}$ cells $/ \mathrm{mL}$ as evident from the scatter plot diagrams in Fig. 1a. A distinct allelic discrimination plot was obtained that clustered gram positive and gram negative seeded samples in different axes. Patient samples screened clustered either in the allele 1 or allele 2 axes, depending on majority concentration of Gram nature of the micro-organisms present in the infected urine samples.

In order to determine the sensitivity of the detection limit, a standard curve was generated using three replicates of each dilution (1E1 to $1 \mathrm{E} 7$ ), by plotting the cell concentration or quantity on the $\mathrm{X}$ axis and the $\mathrm{C}_{\mathrm{T}}$ value on the $Y$ axis (Fig. 2a). The $C_{T}$ values were also plotted in an Excel worksheet to determine the straight line equation $(y=-3.143 x+38.44)$ of the curve. The best fit line (Fig. 2b), had a $\mathrm{R}^{2}$ value of 0.994, which is well within the optimal limit. Figure $2 \mathrm{c}$ is the screen print of the experimental page setup for standard curve experiment in ABI Step One Real Time PCR instrument, software version 2, showing amplification, multicomponent, raw data plot, besides the standard curve. The plate layout with their respective concentrations and the $\mathrm{C}_{\mathrm{T}}$ values for both alleles are also depicted in the diagram. From the standard curve equation, by plotting $\mathrm{X}\left(\mathrm{C}_{\mathrm{T}}\right.$ value $)$, the unknown value of $\mathrm{Y}$ (cell concentration) was determined. The amplifications obtained for the normal and infected samples are shown in Fig. 2d and 2e respectively.

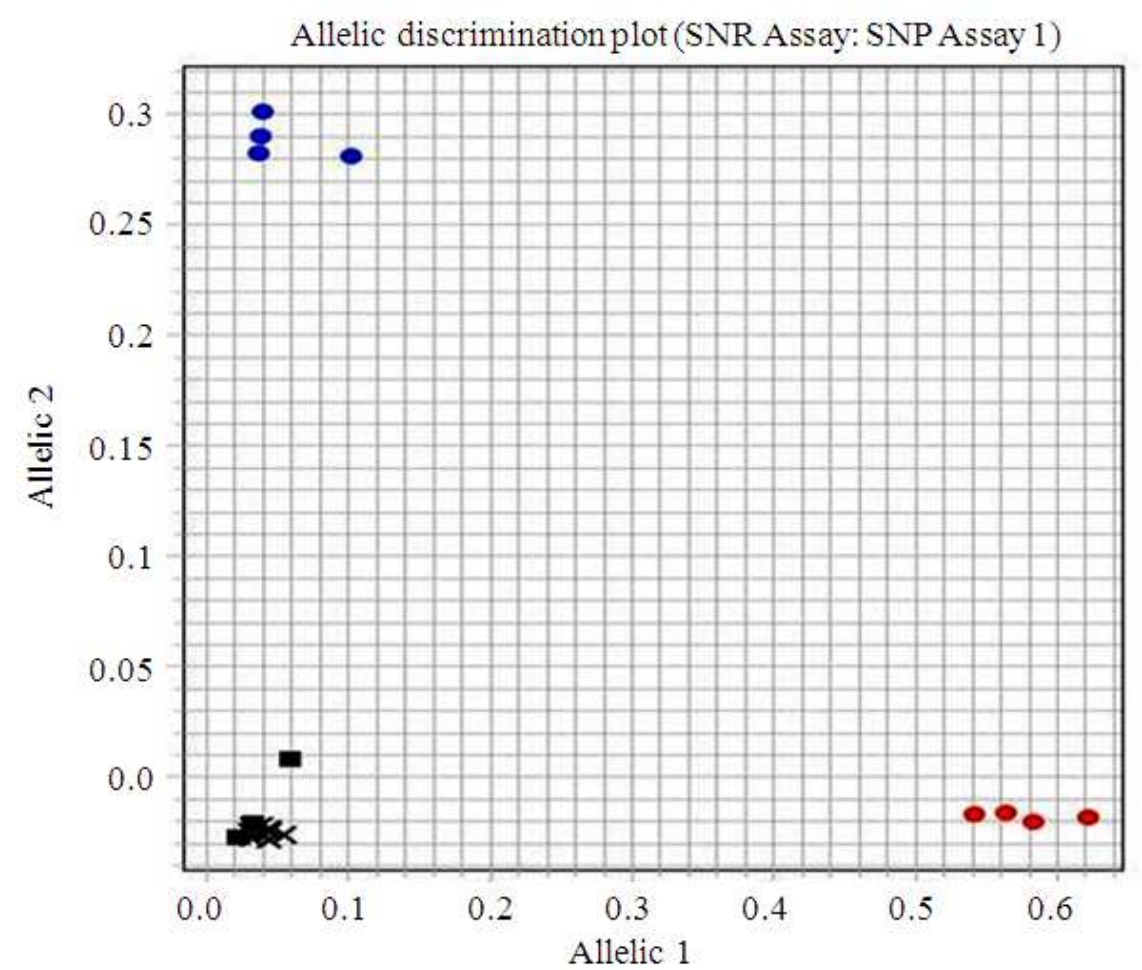

(a) 
Poulomi Nandy et al. / American Journal of Biochemistry and Biotechnology, 9 (2): 133-143, 2013

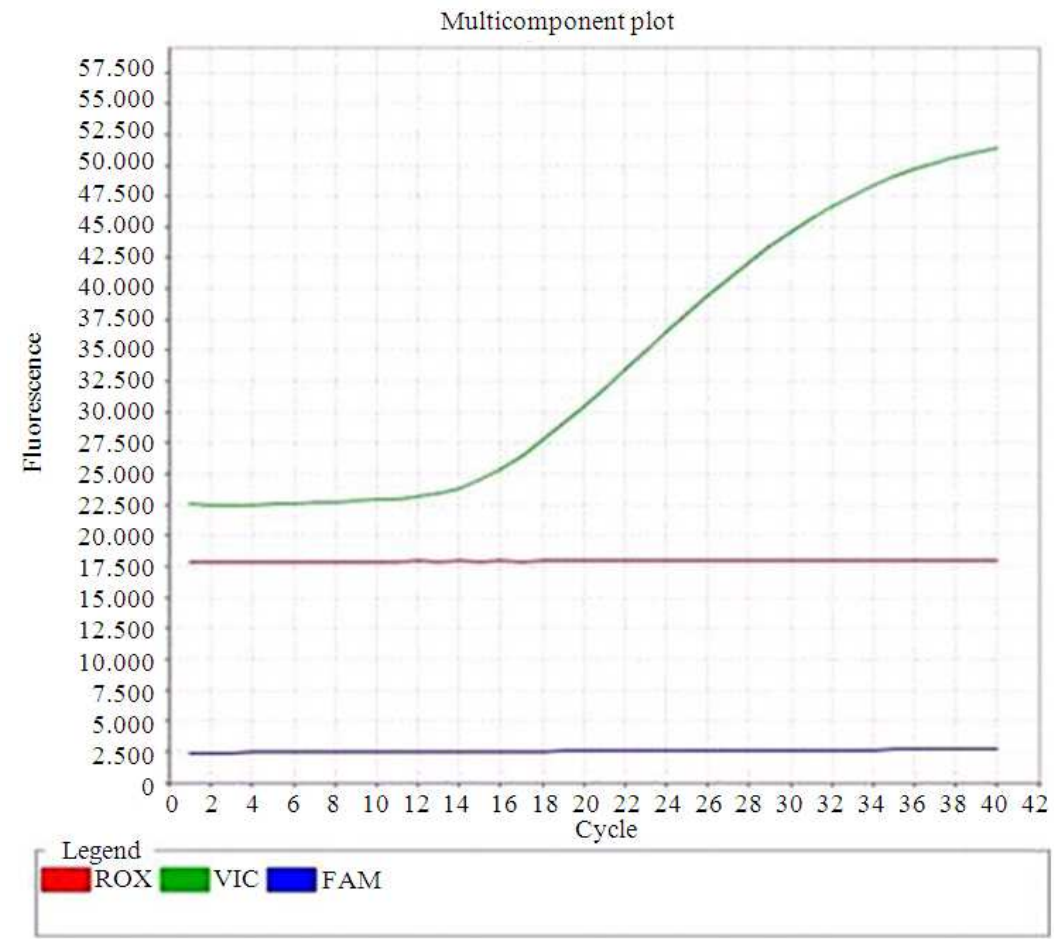

(b)

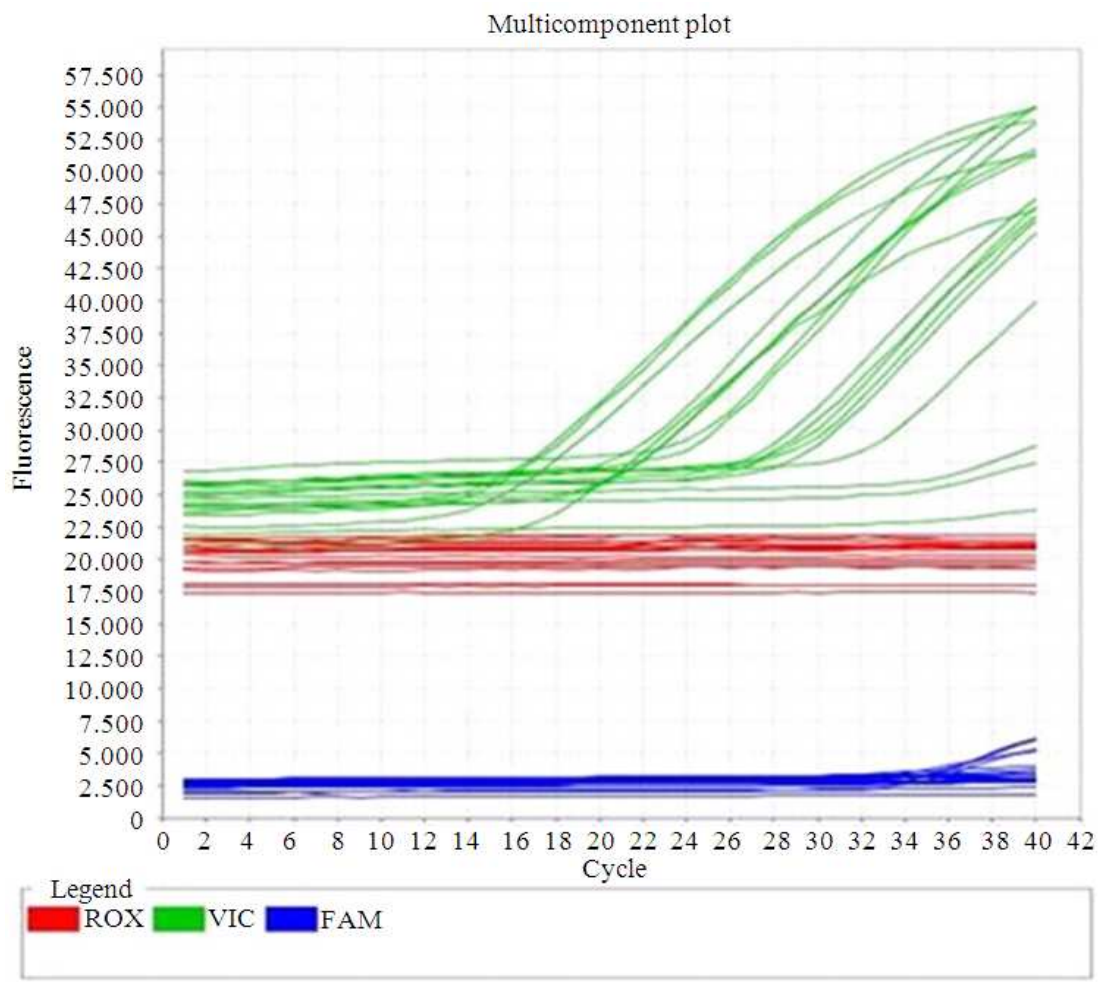

(c) 
Poulomi Nandy et al. / American Journal of Biochemistry and Biotechnology, 9 (2): 133-143, 2013

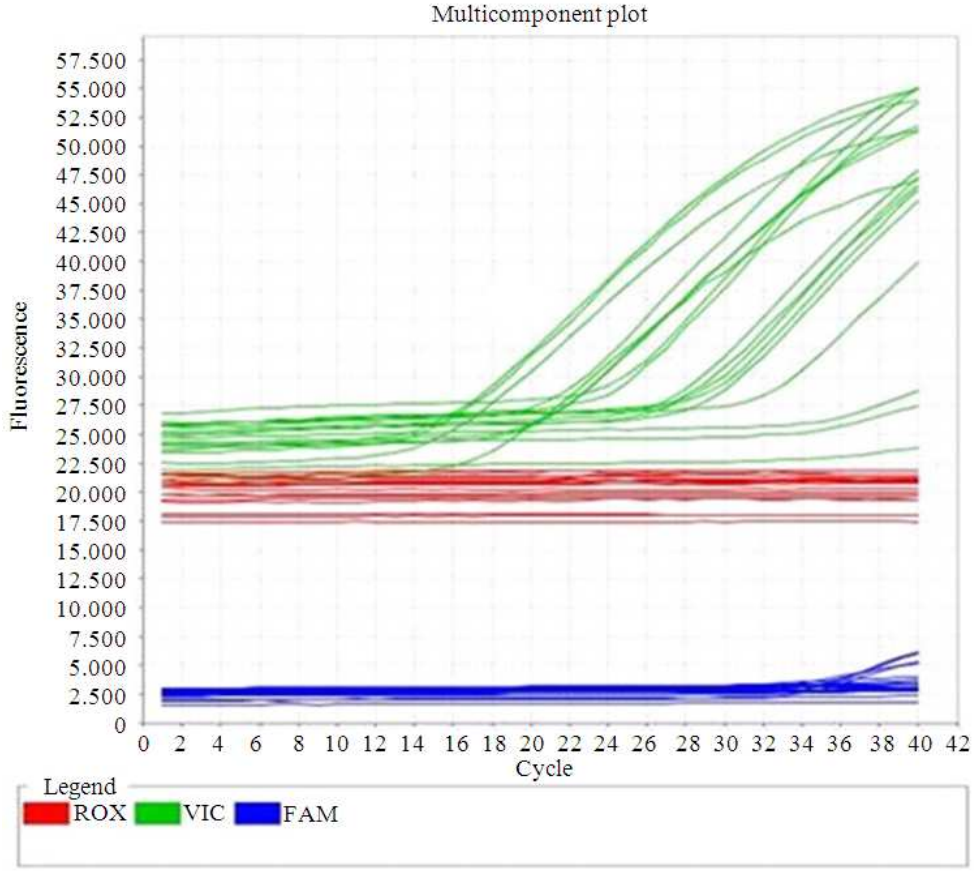

(d)

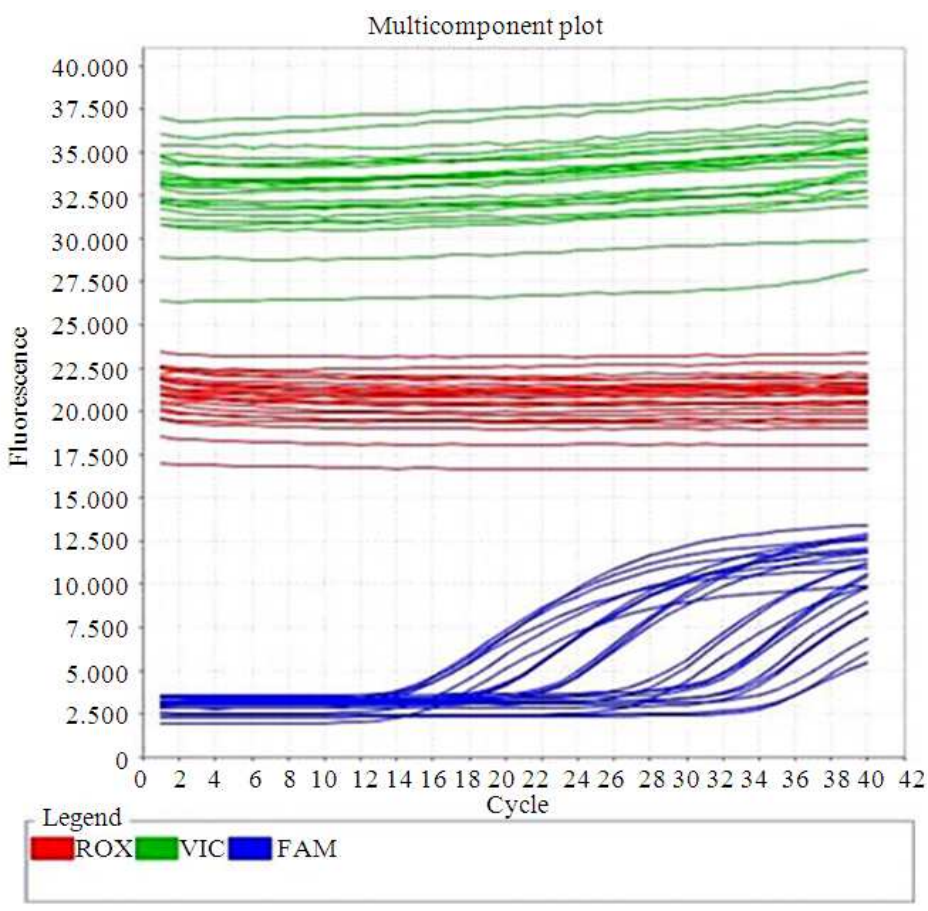

(e)

Fig. 1. (a) Allelic Discrimination/Scatter plot for seeded urine samples of known concentration. (b and c) shows the amplification of VIC probe responsible for Gram positive bacteria and ( $\mathrm{d}$ and e) shows the amplification of FAM probe responsible for Gram negative bacteria 
Poulomi Nandy et al. / American Journal of Biochemistry and Biotechnology, 9 (2): 133-143, 2013

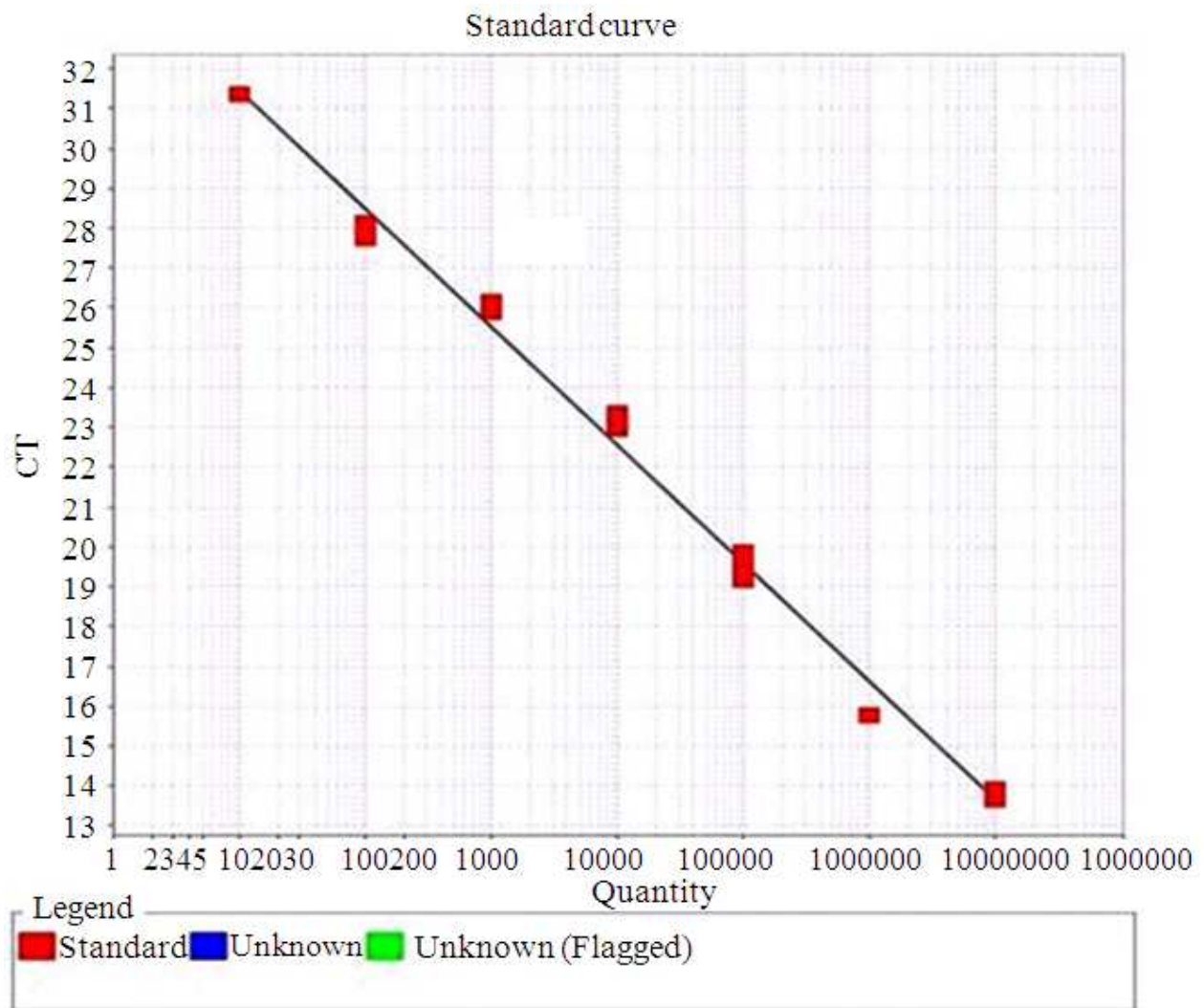

(a)

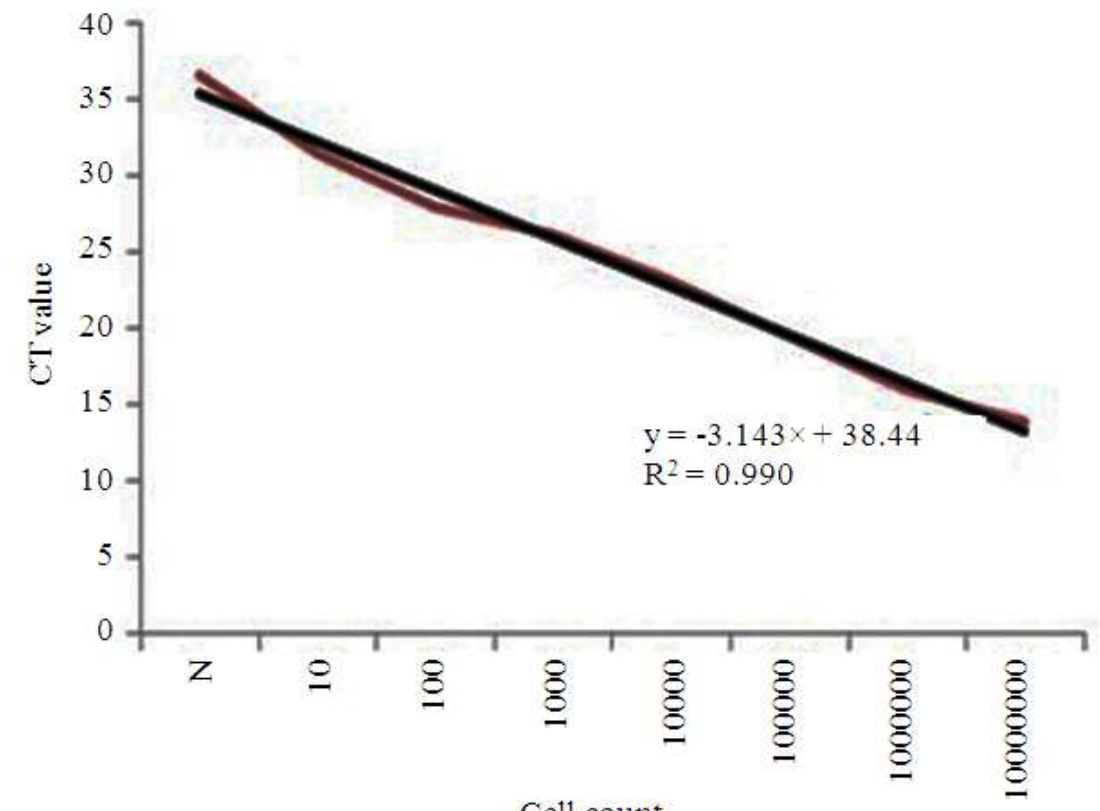

Cell count

(b) 
Poulomi Nandy et al. / American Journal of Biochemistry and Biotechnology, 9 (2): 133-143, 2013

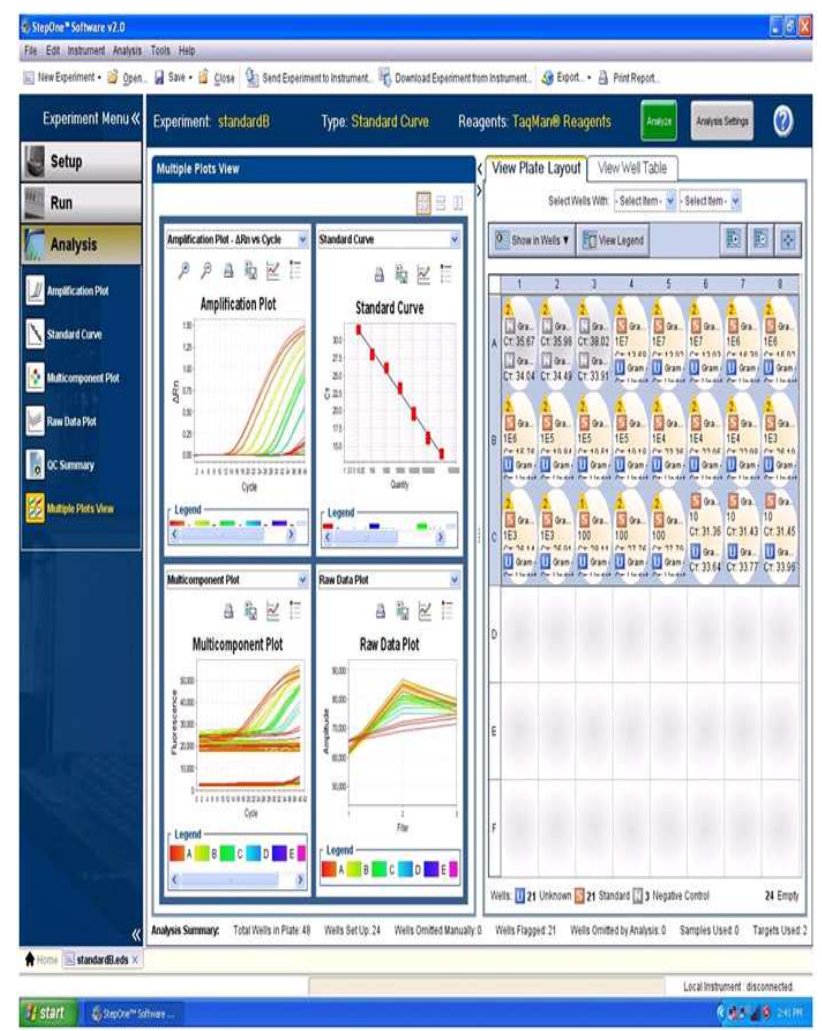

(c)

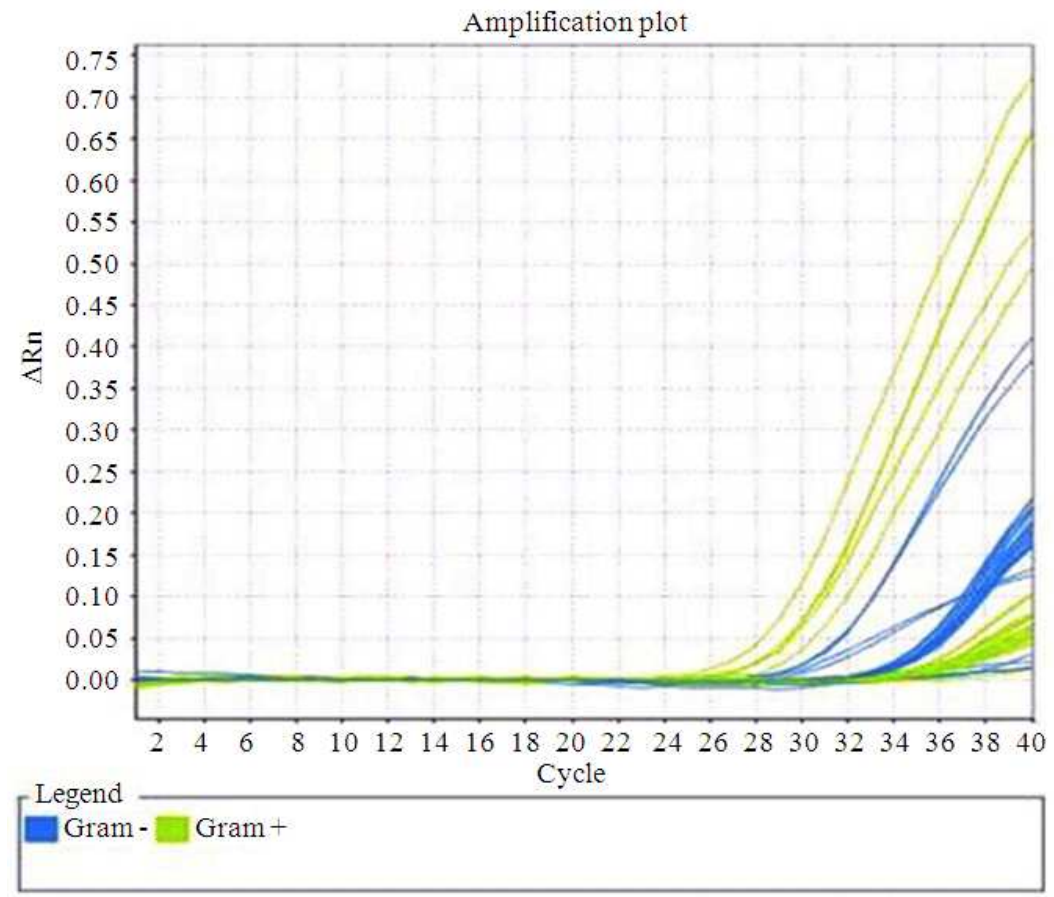

(d) 
Poulomi Nandy et al. / American Journal of Biochemistry and Biotechnology, 9 (2): 133-143, 2013

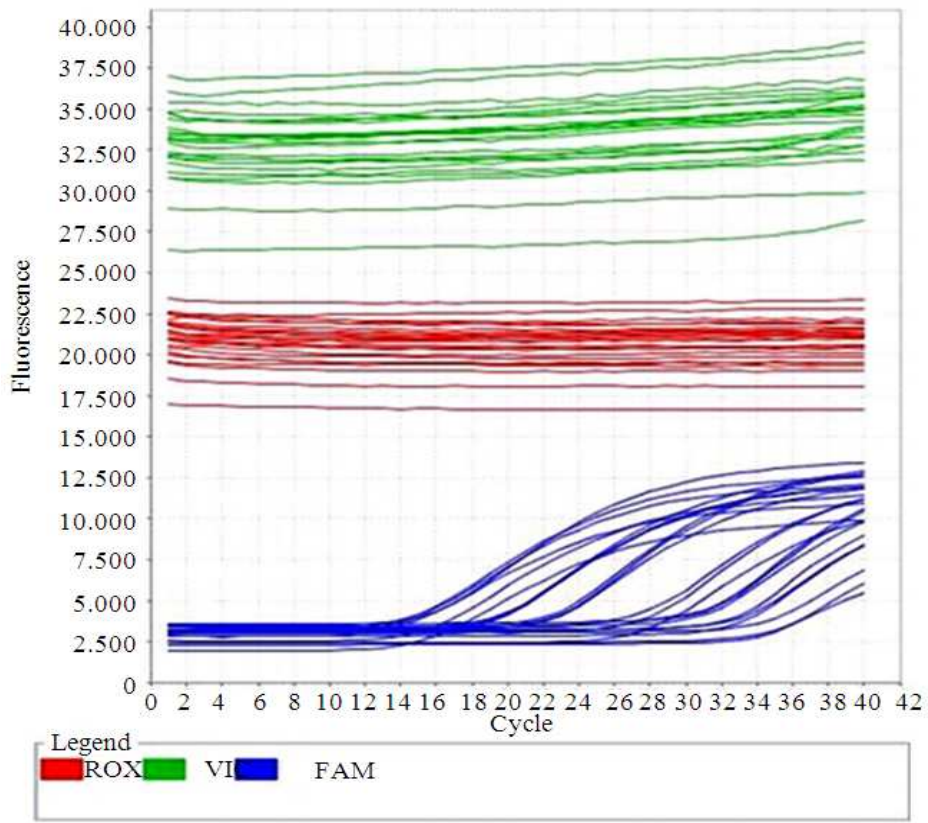

(e)

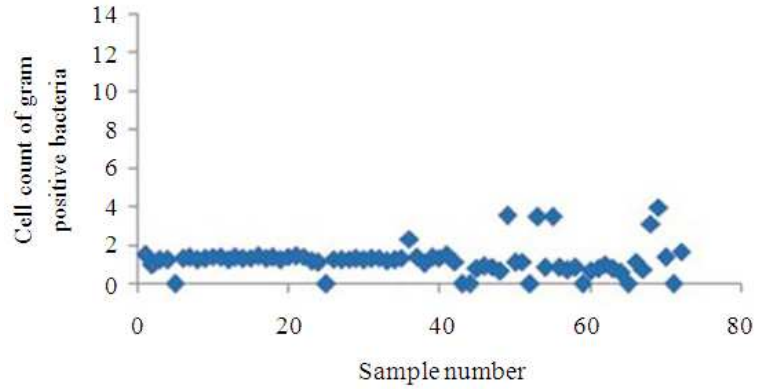

(f)

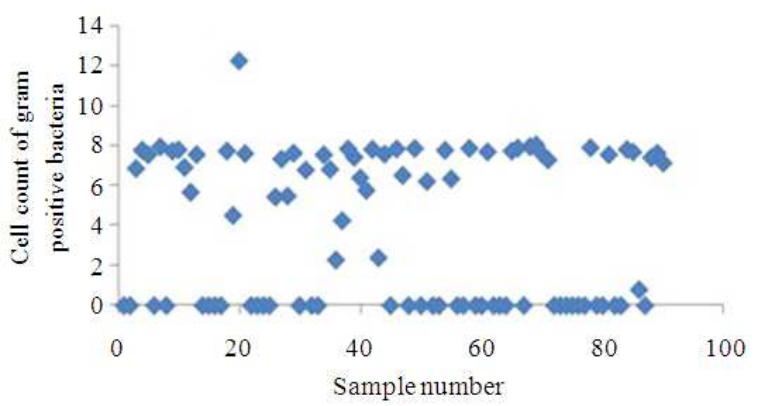

(h)

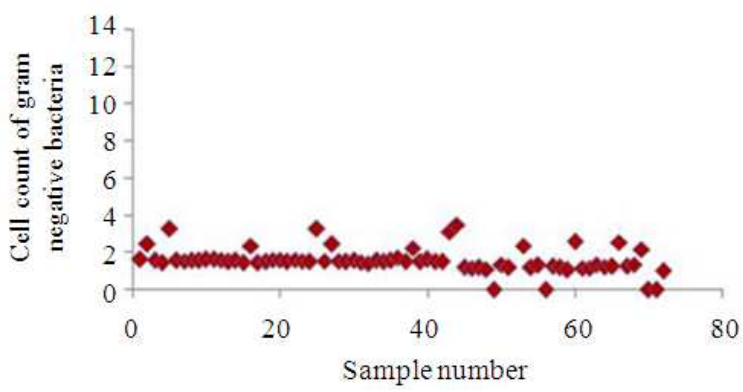

(g)

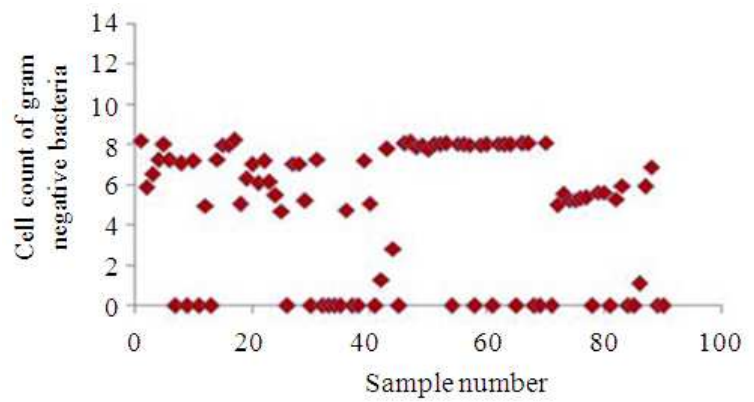

(i)

Fig. 2. (a) Represents the standard curve as obtained in step one software version 2 ABI PCR instrument by performing standard curve experiment and (b) depicts the same standard curve after plotting them in an excel worksheet (c) Show the screen print of the entire experimental setup (d) Show late amplification of normal urine samples and (e) is the graphical representation of variable amplification of the two alleles for random patient urine samples ( $\mathrm{f}$ and $\mathrm{g}$ ) have been plotted with sample number on the $\mathrm{X}$ axis and their cell count calculated from their corresponding CT values by putting them in the standard curve equation on the $\mathrm{Y}$ axis, with normal samples, while (h and i) are their infected sample counterpart 
Table 1. Cell count raw data of the patient urine samples

\begin{tabular}{|c|c|c|c|c|c|}
\hline Subjects & $\begin{array}{l}\text { Gram positive cell count } \\
\text { to the power of } 10\end{array}$ & $\begin{array}{l}\text { Gram negative cell count } \\
\text { to the power of } 10\end{array}$ & Subjects & $\begin{array}{l}\text { Gram positive cell count } \\
\text { to the power of } 10\end{array}$ & $\begin{array}{l}\text { Gram negative cell count } \\
\text { to the power of } 10\end{array}$ \\
\hline 1 & 0.000000000 & 8.184713376 & 53 & 7.767515924 & 0.000000000 \\
\hline 2 & 0.000000000 & 5.859872611 & 54 & 6.340764331 & 8.025477707 \\
\hline 3 & 6.853503185 & 6.506369427 & 55 & 0.000000000 & 8.000000000 \\
\hline 4 & 7.773885350 & 7.222929936 & 56 & 0.000000000 & 7.974522293 \\
\hline 5 & 7.541401274 & 7.996815287 & 57 & 7.866242038 & 0.000000000 \\
\hline 6 & 7.939490446 & 0.000000000 & 58 & 0.000000000 & 7.961783439 \\
\hline 7 & 0.000000000 & 7.076433121 & 59 & 0.000000000 & 7.987261146 \\
\hline 8 & 7.726114650 & 0.000000000 & 60 & 7.691082803 & 0.000000000 \\
\hline 9 & 7.792993631 & 7.187898089 & 61 & 0.000000000 & 8.035031847 \\
\hline 10 & 6.914012739 & 0.000000000 & 62 & 0.000000000 & 8.000000000 \\
\hline 11 & 5.668789809 & 4.964968153 & 63 & 0.000000000 & 7.987261146 \\
\hline 12 & 7.554140127 & 0.000000000 & 64 & 7.729299363 & 0.000000000 \\
\hline 13 & 0.000000000 & 7.264331210 & 65 & 7.875796178 & 8.047770701 \\
\hline 14 & 0.000000000 & 7.961783439 & 66 & 0.000000000 & 8.070063694 \\
\hline 15 & 0.000000000 & 7.980891720 & 67 & 7.952229299 & 0.000000000 \\
\hline 16 & 0.000000000 & 8.219745223 & 68 & 8.041401274 & 0.000000000 \\
\hline 17 & 7.732484076 & 5.057324841 & 69 & 7.585987261 & 8.092356688 \\
\hline 18 & 4.509554140 & 6.315286624 & 70 & 7.283439490 & 0.000000000 \\
\hline 19 & 12.242038220 & 7.022292994 & 71 & 0.000000000 & 4.980891720 \\
\hline 20 & 7.601910828 & 6.089171975 & 72 & 0.000000000 & 5.531847134 \\
\hline 21 & 0.000000000 & 7.175159236 & 73 & 0.000000000 & 5.235668790 \\
\hline 22 & 0.000000000 & 6.124203822 & 74 & 0.000000000 & 5.232484076 \\
\hline 23 & 0.000000000 & 5.471337580 & 75 & 0.000000000 & 5.312101911 \\
\hline 24 & 0.000000000 & 4.697452229 & 76 & 0.000000000 & 5.375796178 \\
\hline 25 & 5.433121019 & 0.000000000 & 77 & 7.891719745 & 0.000000000 \\
\hline 26 & 7.328025478 & 7.044585987 & 78 & 0.000000000 & 5.621019108 \\
\hline 27 & 5.480891720 & 7.031847134 & 79 & 0.000000000 & 5.611464968 \\
\hline 28 & 7.624203822 & 5.197452229 & 80 & 7.547770701 & 0.000000000 \\
\hline 29 & 0.000000000 & 0.000000000 & 81 & 0.000000000 & 5.286624204 \\
\hline 30 & 6.780254777 & 7.261146497 & 82 & 0.000000000 & 5.939490446 \\
\hline 31 & 0.000000000 & 0.000000000 & 83 & 7.802547771 & 0.000000000 \\
\hline 32 & 0.000000000 & 0.000000000 & 84 & 7.681528662 & 0.000000000 \\
\hline 33 & 7.541401274 & 0.000000000 & 85 & 0.786624204 & 1.108280255 \\
\hline 34 & 6.808917197 & 0.000000000 & 86 & 0.000000000 & 5.910828025 \\
\hline 35 & 2.280254777 & 4.735668790 & 87 & 7.401273885 & 6.882165605 \\
\hline 36 & 4.248407643 & 0.000000000 & 88 & 7.624203822 & 0.000000000 \\
\hline 37 & 7.837579618 & 0.000000000 & 89 & 7.127388535 & 0.000000000 \\
\hline 38 & 7.417197452 & 7.197452229 & & & \\
\hline 39 & 6.385350318 & 5.063694268 & & & \\
\hline 40 & 5.764331210 & 0.000000000 & & & \\
\hline 41 & 7.815286624 & 1.302547771 & & & \\
\hline 42 & 2.388535032 & 7.770700637 & & & \\
\hline 43 & 7.573248408 & 2.834394904 & & & \\
\hline 44 & 0.000000000 & 0.000000000 & & & \\
\hline 45 & 7.834394904 & 8.047770701 & & & \\
\hline 46 & 6.515923567 & 8.101910828 & & & \\
\hline 47 & 0.000000000 & 7.859872611 & & & \\
\hline 48 & 7.856687898 & 7.961783439 & & & \\
\hline 49 & 0.000000000 & 7.748407643 & & & \\
\hline 50 & 6.207006369 & 8.009554140 & & & \\
\hline 51 & 0.000000000 & 7.993630573 & & & \\
\hline 52 & 0.000000000 & 8.057324841 & & & \\
\hline
\end{tabular}


The Gram positive and Gram negative $C_{T}$ values were separately plotted for both normal and patient groups (Fig. 2 f to 2i). For control individuals, most of them are scattered within 0 to $10^{2}$, while very few in the range of $10^{4}$, but not above that. The case is just reverse for patient group, where most of the points are scattered within $10^{4}$ to $10^{8}$.

\section{DISCUSSION}

The passive reference dye signal ROX was absolutely constant during the entire experiment. Gram positive samples clustered on the Allele 1 axis of the scatter plot, while Gram negative ones clustered on the allele 2 axis. The probe VIC (allele 1) was responsible for amplification of Gram positive specimens, while FAM (allele 2) for Gram negative ones. Sterile urine sample seeded with a known concentration of Gram positive bacteria shows amplification of only the VIC probe (Fig. 1b) in case of single or multiple samples seeded with the same Gram nature at different concentrations (Fig. 1c). The case is exactly the same for Gram negative seeded samples which shows only amplification of FAM probe (Fig. 1d and 1e), while VIC and ROX are relatively constant. Thus we can say that there was no experimental error.

Without even looking at the CT values in case of control and patient samples (Fig. 2f-2i), one can easily infer from the graph that, there is considerable less amplification in case of normal samples as compared to the infected ones. In case of infected samples amplification starts after 12 cycles only while in control individuals there is no amplification till almost 26th cycle.

Another important notable feature was that, the few points which lie towards 0 to $10^{1}$, in Gram negative plot in the patient group have a higher cell concentration value in the Gram positive plot and vice versa; i.e., those samples are not infected by high concentration of both Gram nature organisms, but only one of either types. For example, in patient 1 and 2 , the gram positive cell count was 0 in both cases, while their respective gram negative counts were $10^{8}$ and $10^{5}$. Similarly in case of the last two sample numbers 88 and 89 , the gram negative cell count was 0 , but the corresponding gram positive count was $10^{7}$ for both. The raw data with cell count value has been provided in Table $\mathbf{1}$ (highlighted), where sample numbers exhibiting this phenomenon have been highlighted (showing 0 in one gram nature plot and a higher cell count value in the other gram nature plot).
Thus, infections caused by non-cultivable bacteria can also be detected by using this culture independent assay. The detection time is drastically brought down from $72 \mathrm{~h}$ to less than $5 \mathrm{~h}$, thus allowing quick administration of antibiotics. The exact cell number of micro-organisms causing the infection can also be determined from the standard curve equation, without the hassle of cultivating them.

\section{CONCLUSION}

A major goal in diagnosis and treatment of patients especially female patients suffering from UTI is the ability to rapidly detect the characteristics of infecting microbes. We have used Real Time PCR in the differentiation of Gram nature of bacteria present in UTI patients using a consensus real-time PCR protocol that allows detection of spiked bacterial 16S rDNA from urine samples within $5 \mathrm{~h}$ along with the corresponding cell count of both/either Gram positive and negative organisms present. The similar technique could be used for pathogen detection in case of Septicemia.

\section{ACKNOWLEDGEMENT}

The researcher acknowledge the support of the West Bengal University of Technology for the computational facility and the laboratories; University Grant Commission-Inter University Consortium as well as Department of Atomic Energy, Government of India under the BRNS scheme for the student fellowship and Department of Atomic Energy, Government of India under the BRNS scheme for financial assistance.

\section{REFERENCES}

Barret, S.P., M.A. Savage, M.P. Rebec, A. Guyot and N. Andrews et al., 1999. Antibiotic sensitivity of bacteria associated with community-acquired urinary tract infection in Britain. J. Antimicrob. Chemother., 44: 359-365. DOI: 10.1093/jac/44.3.359

Belgrader, P., W. Benett, D. Hadley, G. Long and J.R. Mariella et al., 1998. Rapid pathogen detection using a microchip PCR array instrument. Clin. Chem., 44: 2191-2194. PMID: 9761255

Bergeron, M.G. and M. Ouellette, 1995. Diagnosing bacterial infectious diseases in one hour: An essential upcoming revolution. Infection, 23: 69-72. DOI: $10.1007 / \mathrm{BF} 01833867$ 
Bittar, F., H. Richet, J.C. Dubus, M.R. Gaubert and N. Stremler et al., 2008. Molecular detection of multiple emerging pathogens in sputa from cystic fibrosis patients. Plos. One, 3: 1-7.

Butcu, M., S.S. Akcay, A.S. Inan, S. Aksaray and D.O. Engine et al., 2011. In vitro susceptibility of enterococci strains isolated from urine samples to fosfomycin and other antibiotics. J. Infect. Chemother., 17: 575-578. DOI: 10.1007/s10156011-0212-7

Carroll, N.M., E.E.M. Jaeger, S. Choudhury, A.S Anthony and M. Dunlop et al., 2000. Detection of and discrimination between gram-positive and gramnegative bacteria in intraocular samples by using nested PCR. J. Clin. Microbiol., 38: 1753-1757. PMID: 10790093

Dharmadhikari, S.M. and S.A. Peshwe, 2009. Molecular level studies on multiple antibiotic and serum resistance in UTI pathogens. Ind. J. Biotechnol., 8: $40-45$.

Foxman, B., 2003. Epidemiology of urinary tract infections: Incidence, morbidity and economic costs. Dis. Mon., 49: 53-70. PMID: 12113866

Ishaq, M., A.K. Akhund, M.B. Laghari and M. Sabir, 2011. Urinary tract stone disease serum and urinary calcium in stone formers and non-stone formers. Professional Med. J., 18: 243-245.

Karlowsky, J.A., M.E. Jones, C. Thornsberry and I. Critchley et al., 2001. Prevalence of antimicrobial resistance among urinary tract pathogens isolated from female outpatients across the US in 1999. Int. J. Antimicrob. Agents, 18: 121-127. DOI: 10.1016/S0924-8579(01)00369-7

Leclerq, R., E. Detlot, J. Duval and P. Courvalin, 1988. Plasmid mediated resistance to vancomycin and teicoplanin in Enterococcus faecium. N. Engl. J. Med., 319: 157-161. DOI: 10.1056/NEJM198807213190307
Mathai, D., R.N. Jones and M.A. Pfaller, 2001. Epidemiology and frequency of resistance among pathogens causing urinary tract infection in 1,510 hospitalized patients: A re-port from the SENTY Antimicrobial Surveillance Pro-gram (North America). Diag. Microbiol. Infect. Dis., 40: 129-136.

Nicolle, L.E., L.J. Strausbaugh and R.A. Garibaldi, 1996. Infections and antibiotic resistance in nursing homes. Clin. Microbiol. Rev., 9: 1-17. PMID: 8665472

Picard, F.J. and M.G. Bergeron, 1999. Rapid diagnosis of bacterial infections using technologies based on nucleic acid detection. Can. J. Infect. Dis., 10: 16-24.

Picard, F.J. and M.G. Bergeron, 2002. Rapid molecular theranostics in infectious diseases. Drugs Discovery Today, 7: 1092-1101. DOI: 10.1016/S13596446(02)02497-2

Ramlakhan, S.L., D.P. Burke and R.S. Goldman, 2011. Dipstick urinalysis for the emergency department evaluation of urinary tract infections in infants aged less than 2 years. Eur. J. Emerg. Med., 18: 221-224. DOI: 10.1097/MEJ.0b013e3283440e88

Shigemura, K., T. Shirakawa, H. Okada, K. Tanaka and S. Kamidono et al., 2005. Rapid detection and differentiation of Gram-negative and Gram-positive pathogenic bacteria in urine using TaqMan probe. Clin. Exp. Med., 4: 196-201. DOI: 10.1007/s10238004-0056-x

Tang, Y., G.W. Propcop and D.H. Persing, 1997. Molecular diagnostics of infectious diseases. Clin. Chem., 43: 2021-2038. DOI: 10.1097/MOP.0b013e328320d87e

Ultley, A.H.C., C.H. Collins, J. Naidoo and R.C. George, 1988. Vancomycin-resistant Enterococci. Lancet, 331: 57-58. 